\section{Questión}

Periodismo / Comunicación ISSN 1669-6581
- Av. $44 \mathrm{~N}^{\circ} 676,1^{\circ}$ piso

CP 1900 - La Plata - Argentina

www.perio.unlp.edu.ar/question

Crónica de una muerte (no) anunciada: a la pesca de categorías ¿perdidas?

Esp. Marisol B. Iturralde

DOI: https://doi.org/10.24215/16696581e314

\title{
Crónica de una muerte (no) anunciada: a la pesca de categorías ¿perdidas?
}

\section{Chronicle of an announced death (not): to the fishing of categories lost?}

Esp. Marisol B. Iturralde / linkedin.com/in/marisol-iturralde-16474021 Rectora en el Instituto de Formación Docente Continua de Villa Mercedes (SL)(IFDCVM); Integrante del Programa de Fortalecimiento a las Prácticas de Investigación en la FCHJyS-UNSL y formadora de profesores desde hace más de 30 años, en diferentes instituciones de Nivel Superior. Ama enseñar, actuar y juntarse con sus amigas

“...cuando llegas a ese momento en el que la teoría logró en apariencia resolverlo todo, pero le quedó un detalle que no, todo se viene abajo y entras en una situación crítica en la que tienes que inventar algo" (Oyarzún, 2020)

Siempre me interesó mucho la cuestión de las nuevas Tecnologías de la Información y de la Comunicación (TIC) y su incidencia en la construcción de los sujetos y de las nuevas formas de relacionamiento, en la contemporaneidad. Como hace mucho tiempo me dedico a formar profesores y a mirar, en particular, la escuela y el aula, direccioné mi foco hacia ese objeto de estudio; la realidad siempre me fue ofreciendo algunas pistas para analizar las relaciones entre la educación y las TIC y, a partir de algunas categorías teóricas, balbucear algunas explicaciones sobre lo observado. Debo valerme de este preludio para introducir el presente ensayo porque lo antes analizado a partir de algunas perspectivas teóricas de mi interés, en el contexto actual de pandemia, aislamiento social y virtualidad escolar, ya no tienen el mismo sentido. La crónica sobre los propios recorridos explicativos serán el 
puntapié para pensar sobre la educación en tiempos de pandemia y conjeturar algo sobre el presente, prácticamente, como la contracara de lo antes pensado.

\section{Caso 1: TIC y vigilancia}

En el 2016 escribí un ensayoi donde reflexionaba sobre un caso acontecido, el año anterior, en un colegio secundario de la ciudad de Mendoza dependiente de la UNCuyo. El suceso, que tomó trascendencia en los medios nacionales, puede resumirse en los siguiente: la profesora de Lengua Laura Cogni de Bru - insulta a sus alumnosii del último año del secundario debido a que no prestan atención en su clase y a su bajo rendimiento académico, augurándoles un destino de fracaso en la continuidad de sus estudios superiores. Dicha profesora fue grabada por un alumno de la clase mientras emitía su discurso descontrolado y se registra la prueba que desembocó, luego, en la suspensión por treinta días de la profesora involucrada, como medida sancionatoria. Pero el hecho no culminó con el registro fílmico, sino que lo acontecido fue puesto inmediatamente en las redes (Facebook), multiplicándose la posibilidad de ver, y por tanto de juzgar y valorar lo que en otro tiempo hubiese sido resuelto, únicamente, por medio de un careo entre quienes se calificaban como los victimarios y/o víctimas de la situación aludida. Me interesó el caso porque, a mi criterio, daba cuenta de la potencia panóptica del uso de los celulares en el aula (con sus cámaras filmadoras) y porque dejaba entrever concepciones sobre lo público, por parte de los alumnos involucrados, en lo que se supone es un lugar de encierro cuyo acontecer transcurre, desde hace siglos, entre muros. Asimismo, respecto al caso mencionado, observé las opiniones de los padres, el gremio, los especialistas y la comunidad mendocina sobre el uso de las TIC en el aula en tanto registro de prueba o escrache del otro. Dicha situación, según mi parecer, puso en franca cuestión las relaciones de gobierno al interior del aula y se hizo evidente que los celulares, como una de las tantas tecnologías de la información y la comunicación que pueden ser parte del paisaje escolar, adquirían una dimensión más política que didáctica. Presupuse que la idea de gobierno del aula (Dussel y Caruso,1999) tal como se concibió en los inicios de la escuela elemental en Europa, allá por el Siglo XVII, se derrumbaba progresivamente y me pregunté: ¿Quién gobierna el aula? ¿Quién es depositario del saber? ¿El que sabe sobre la disciplina como contenido o el que sabe maniobrar los artilugios de lo disciplinario? ¿Son los celulares con sus cámaras filmadoras elementos de micro poder que denuncian lo que de otro modo se acallaría? ¿Qué relación hay entre los ciber jóvenes (en este caso, alumnos) y los usos políticos de la tecnología como medio de visibilización de las relaciones sociales (en este caso, en el ámbito escolar)? 
Por entonces, intentaba explicar que la mirada omnipresente del docente, que históricamente tuvo mucho que ver en el gobierno de la clase, ya no era un atributo primordial, sino que el poder que se distribuía entre quienes disponían de aparatos tecnológicos en la clase (los más clásicos, los celulares). De la vieja y clásica pregunta profesoral: ¿Los alumnos me estarán entendiendo cuando enseño?, presumí que estábamos pasando a una más epocal e inquietante: ¿Los alumnos me estarán filmando? La perspectiva Foucaultiana acerca de la escuela como un lugar de encierro y disciplinamiento de los cuerpos, que desarrolla a través de la metáfora del "panóptico"iii, me posibilitó entrever la dimensión política de los dispositivos tecnológicas al interior del aula y los planteos de corte didáctico - acerca de habilitar su uso, o no -, ya no me parecían relevantes. Intuía que un nuevo orden escolar estaba emergiendo y que los viejos formatos educativos iban terminar trastocándose, a partir de la inclusión de aquéllos.

\section{Caso 2: TIC y coordenadas de la clase}

Otro de los casos que recorrió el mundo a finales de 2015, diferente al anterior, pero con un efecto similar sobre el trabajo docente, fue el de un profesor universitario de Uruguay - Leonardo Haberkorn quien escribe una carta donde expresa su renuncia a enseñar debido a la falta de atención y rendimiento académico de sus alumnos por el uso abusivo de dispositivos tecnológicos en sus clases. En su epístola interpela a los jóvenes y no ahorra en descalificaciones sobre sus comportamientos estudiantilesiv. Entre otras cosas, el mencionado profesor, expresa con desazón "...vi a gente dormirse en el salón y a otros chateando en WhatsApp o Facebook (...) Caras absortas. Desinterés. Un pibe despatarrado mirando su Facebook. Todo el año estuvo igual".

De acuerdo al análisis que realicé dos años después de lo acontecido, observo que lo común de ambos casos tenía que ver con el corrimiento de los profesores de su función de gobierno de lo que ocurre dentro del aula, atribuyendo las causas del desmanejo de sus clases al desinterés de los jóvenes por el conocimiento y al uso permanente de dispositivos tecnológicos que interrumpían u obstaculizan el devenir de la misma; dispositivos que también eran utilizados como elementos de control, prueba y/o defensa contra supuestos ataques o desbordes de los docentes (desde los hechos tomados como ejemplo, hasta no hace mucho tiempo atrás, se han sucedido innumerables casos similares).

Se sabe que los celulares están en la clase y que con ellos se pueden realizar diferentes actividades didácticas acordadas entre alumnos y profesores. Lo que no siempre se sabe, o no se ve, es qué otra 
utilidad se les puede a dar en cualquier momento de la cotidianeidad escolar, cuyo uso supera cualquier posibilidad de cálculo.

\section{Explicaciones 1: del Panóptico al Sinóptico}

Sibilia (2014) expresa que la escuela moderna como lugar de confinamiento se ha vuelto ineficaz y que las sólidas paredes de antaño (cada vez más blindadas con rejas) "se dejan filtrar por las ubicuas redes". Las formas de control de la sociedad disciplinaria que describiera Foucault, se transforman en la contemporaneidad de un modo inédito. Como dice la autora mencionada, las tecnologías y las redes están "complejizando las paredes" y, en muchas situaciones escolares, operan desde su potencia panóptica. Uno de los aspectos que dan cuenta del alcance de estas mutaciones escolares, y que ponen en jaque los ideales de la Modernidad, es la inclusión en el aula de las nuevas tecnologías de la información y la comunicación. Por un lado, entre las más utilizadas, se pueden mencionar los dispositivos y computadoras móviles (notebooks, netbooks, tablets, teléfonos celulares, smartphones), los que contienen diversas funciones y aplicaciones: bluetooth, whatsapp, acceso a internet, reproductores de audio y video, creación de documentos, juegos, cámara fotográfica, filmadora, etc. Por otro lado, se destaca la diversificación de espacios de socialización e intercambio: redes sociales, comunidades virtuales, blogs, wikis, youtube, chat, juegos en red, etc. A diario podemos observar que quienes están en un aula - tanto alumnos como profesores - no pueden sustraerse a su uso y que el espacio territorial y el espacio virtualv se funden de un modo inédito. En este sentido, Burbules y Callister expresan que "las nuevas tecnologías no sólo constituyen un conjunto de herramientas, sino un entorno - un espacio, un ciberespacio - en el cual se producen las interacciones humanas" (2008, p.19). En el marco de esta visible tecnosociabilidad, los estudiantes interpelan la tradición en la que se apoyan viejas prácticas docentes basadas sólo en estructuras comunicacionales analógicas, ya que son ellos "quienes más exploran su potencial y quienes más diversifican su aplicabilidad" (Peirone, 2017).

Al respecto, Sibilia (2012) afirma que las nuevas tecnologías de comunicación - sobre todo, los aparatos móviles de acceso a las redes informáticas - $y$, particularmente, los modos de vida que ellos implican, están afectando el funcionamiento de la escuela en clave de la Modernidad, induciéndonos a problematizar los factores involucrados en el creciente desacople entre los nuevos modos de ser y estar en el mundo y las viejas instalaciones y tradiciones escolares. En sintonía con lo que expresan los autores mencionados, Cabello (2010) discurre sobre los "entornos tecno culturales", expresando que "la oferta y disposición de un conjunto cada vez más variado de dispositivos tecnológicos - en este caso, en 
general digitales - contribuye con la configuración de un tipo particular de escenario en el cual se desarrollan los intercambios, el que se diferencia sustantivamente de otros que predominaron en otros momentos históricos". Este escenario, también denominado como "cultura digital", atraviesa a la escuela $y$, particularmente el aula, produciendo una probable alteración del orden social instituido, en tanto ésta no queda al margen de un fenómeno de amplitud mayor que afecta la vida social y los modos cotidianos de interacción - y de control - entre los sujetos.

La digitalización de las relaciones se vincula con la transformación de los modos de intercambio y de ejercicio del poder, propios de las "sociedades disciplinarias", hacia las "sociedades de control". Asistimos a "una crisis generalizada de todos los lugares de encierro (...) Son las sociedades de control las que están reemplazando a las sociedades disciplinarias" (Deleuze, 1991, p.1). Los dispositivos modernos de disciplinamiento, que Foucault describiera minuciosamente, tambalean frente a lo que Deleuze (ibídem) designa como un nuevo "monstruo", caracterizado por "(...) formas ultrarrápidas de control al aire libre, que reemplazan a las viejas disciplinas que operan en la duración de un sistema cerrado (...) En las sociedades de control lo esencial no es ya una firma ni un número, sino una cifra: la cifra es una contraseña" (1991, p.1-4). En la misma obra, el autor mencionado nos invita a pensar sobre el "programa" de las sociedades de control que procuran un nuevo y progresivo régimen de dominación el que, cual una serpiente, se mueve de manera ondulatoria y zigzagueante según la lógica del mercado en espacios que no son sólo de encierro (como los de las sociedades disciplinarias), sino que son abiertos y mediados tecnológicamente.

La utopía panóptica de una "ciudad perfectamente gobernada" tantas veces aludida para representar los artilugios del biopoder escolar, va cediendo lugar a otros modos menos evidentes, pero, tal vez, igualmente versátiles e invisibles de conducción de los otros, configurando una forma de poder que no actúa directamente sobre los cuerpos de los sujetos para producir individuos dóciles, tal y como era propio en los regímenes disciplinarios, pero no menos efectiva en la modelización de comportamientos. En las sociedades de control, sus mecanismos ya no van enfocados al cuerpo individual, sino a un cuerpo social (Gallo, 2010, p.2). Los individuos están representados en "(...) un nuevo cuerpo: cuerpo múltiple, cuerpo de muchas cabezas, si no infinito, al menos necesariamente innumerable" (Foucault, 2003, citado por Saura, G. y Luengo Navas, J., 2015, p.118). Con Lazzarato, que fue una revelación teórica para entonces, sumé a este planteo la noción de "noo-políticas"; esto es, nuevas relaciones de poder que se ejercen a distancia a través de medios artificiales vinculadas a "la emergencia de la cooperación entre cerebros, al funcionamiento por flujos y redes, al desarrollo de dispositivos 
tecnológicos de acción a distancia: teléfono, cine, TV, internet, etc., y a la formación de los públicos, es decir, el ser conjunto que tiene lugar en el tiempo" (2006, p.92). Según Di Paolo (2014) "Esta acción política no sustituye a los anteriores mecanismos de poder, sino que se agencian los unos a los otros. Las noo-políticas entendidas como 'coordinaciones', dirigen y organizan a los otros dispositivos (disciplinas, biopoder), mientras que operan en el nivel más desterritorializado".

Bauman, termina de dar luz al panorama, acuñando un término para nombrar este fenómeno: el "sinóptico", representado en las tarjetas de crédito, las tarjetas de puntos de los supermercados, las bases de datos de éstas, y las redes sociales; nuevos panópticos elegidos por los vigilados para tener acceso a "todo lo que merece la pena, a costa de revelar su información" (2001, p.69). Mientras el panóptico permitía disciplina mediante la amenaza del castigo, el sinóptico seduce. La misma seducción que producen las TIC, asimiladas a los ideales de innovación, velocidad y comodidad, a pesar de que, probablemente, los efectos de su uso dejan a expensas del otro el comando de lo que (nos) ocurre. Al decir de Bauman, se han invertido los roles, respecto del dispositivo panóptico, y ahora son muchos los que se dedican a observar a unos pocos.

Evidentemente, en esta hibridación entre sociedades disciplinarias y de control, los espacios virtuales y reales que "se limitan en forma difusa" (Lion, 2006, citado por Paredes, A. y otros, 2015) y, además, alteran las concepciones convencionales de "lo público y lo privado y las demarcaciones entre sus fronteras" (ibídem, 2015).

\section{Caso 3: Educación, Formación Docente y coronavirus}

En la crónica de casos y breves ideas teóricas expuestas, que empezaron a acompañar mis preocupaciones en torno a la inclusión de las TIC en la escuela, en general, y en el aula y su gobierno, en particular, ya podía inferir algunos modos un tanto trastocados de funcionamiento, en relación a las coordenadas que organizaban el trabajo docente, el de los estudiantes y sus vínculos con el conocimiento: la noción de tiempo, de espacio, de atención, de comunicación e, incluso, la de validez del conocimiento. Me imaginé muchos escenarios posibles. Con mis alumnos hicimos muchas veces el ejercicio de pensar "las aulas del futuro" y reflexionar sobre el hecho de que ellos serían los docentes del 2040. Ante estas preguntas, pude ser testigo de una perplejidad inusitada que se reflejada en sus rostros; pero, ni aun siendo adictos a Black Mirrorvi, pudimos anticiparnos lo que el COVID-19 nos está haciendo experimentar. 
Entonces, y ya no sólo como formadora de docentes sino como Rectora de una Institución que se dedica a ello, además de preguntarme acerca del gobierno del aula a partir de la inclusión de las TIC en la vida escolar, me interpela cómo gobernar una Institución, en y desde el espacio virtual "total", sin métodos de educación combinada, ni medias tintas. "Total", desde que nos azota el COVID-10, es: jtotal!

Lo que hasta marzo de 2020 era una preocupación teórica y práctica de cualquier institución que iba hacia la virtualidad, hoy es una realidad que me/nos ha dejado al desnudo de categorías explicativas; como dice Oyarzún (2020), al referirse a la experiencia global en tiempos de pandemia, "evidentemente, no hay episteme (...) contamos con la doxa, con la opinión, que son las formas a las que se apela a la hora de orientarse en el mundo por medio de la experiencia" En este sentido, y muy a tientas, estamos intentando ordenar la vida institucional apoyándonos en sistemas de colaboración y asistencia por parte de quienes "surfean" mejor en el espacio digital. A falta de explicaciones frente a lo que nos tomó por asalto, los directivos y docentes formadores nos asimos a opiniones de los más expertos y a estrategias prácticas (pero no por ello menos complejas en su diseño), acuñando instructivos, tutoriales, consultorías, asesoramientos y cursos varios sobre administración de aulas virtuales y plataformas meet. Nos vamos volviendo "youtubers en educación, con más likes que un influencer" (dice alguno de los tantos audios circulantes respecto al nuevo rol docente), expertos en aplicaciones, edición de imágenes, escritura en la virtualidad, en responder full time y mantener la calma para promover que alguien, del otro lado de la pantalla, se sienta realmente "alguien", desde su condición de alumno. Durante años nos hemos preocupado hasta el desvelo sobre cómo captar la atención de nuestros interlocutores estudiantiles, en tanto ahora, ellos son los que buscan nuestra atención y piden "ser vistos" (agregados, registrados) en las aulas del campus virtual institucional o en un sitio que cumpla tal efecto.

Es claro que en las Instituciones de Formación Docente nos confrontamos a un doble desafío: por un lado, intentar dar respuesta a qué cuestiones pedagógicas nos inquietan acerca de la mudanza de las clases desde el espacio territorial al espacio digital y, por otro lado, construir un saber hacer en la virtualidad total - que no sólo implica disponer de recursos tecnológicos - para que los estudiantes no sólo comprendan la disciplina, sino para que, a partir de ésta, amplíen su comprensión del mundo, piensen al mundo y, además, aprendan modos de cómo hacerlo sobre otros: sus futuros alumnos. Me pregunto: ¿Cómo enseño a enseñar sobre un soporte que desconozco o que conozco medianamente? ¿Cómo re direcciono las tradiciones que se sedimentaron en la presencialidad hacia un espacio que elude los artilugios del gobierno del aula y del clásico rol profesoral? ¿Cómo se construyen los vínculos pedagógicos en las mediaciones tecnológicas? ¿Cómo pienso cada componente del sistema didáctico 
cuando no dispongo de la mirada del estudiante que me ayuda "in vivo" a revisar mi propio trabajo docente desde los emergentes que se producen en las interacciones directas?

Caímos en la virtualidad por razones más que comprensibles desde el punto de vista sanitario, no obstante, las primeras apreciaciones sobre la educación virtual son tan variadas como las competencias docentes para afrontar este desafío.

Más que explicaciones, conjeturas 2: del panóptico y el sinóptico, al coronopticón

En el Caso 1 y 2 podemos observar cómo los dispositivos tecnológicos en el aula vinieron a intervenir el espacio de lo público, ya sea porque fueron utilizados como elemento de prueba de algo que transcurría en tiempo real, filmando lo que ocurría, ya sea porque los estudiantes los convirtieron en "intrusos" -con sus mundos privados socializando en las redes sociales- desconociendo, probablemente, lo que ocurría en la clase. Hace tiempo que en el espacio territorial del aula el límite entre lo público y lo privado se viene desdibujando; más bien lo privado parecía incidir y afectar, de modo más o menos regulado, según cada institución, el espacio público que constituye la clase y sus rituales. No obstante, en tiempos de educación virtual total, pareciera que este fenómeno se muestra en su reverso: lo público, a través de la educación formal, se metió en los hogares sin pedir permiso. Ahora, es el profesor quien, legitimado por políticas de Estado (tratando de hacer lo mejor posible en su trabajo docente), llega a cada uno de sus destinatarios a modo de un "coronopticón": un panóptico en tiempos de coronavirusvii. Según Sánchez (2020) "se habla del "coronópticon", en referencia a la nueva invasión a la privacidad. De cómo la tecnología centraliza la información de los ciudadanos y entra en un conflicto inédito con las libertades individuales: el Gran Hermano en tu bolsillo". Si bien en el artículo, esta autora hace referencia a las formas de vigilancia estatal sobre las personas, para el control de la pandemia, me pareció un término que podría ponernos a pensar los nuevos modos de "invasión" de lo escolar en las casas de los estudiantes a través de la mirada del docente, expandida exponencialmente, en tiempo real, o no, y en un espacio ilimitado. Bien viene a colación de lo que expreso el caso del alumno que se durmió durante una clase online; lo llamativo no es que un alumno se duerma en clase, lo llamativo es que estaba en su camaviii.

Las "aulas aumentadas", ampliadas o expandidas, de las que nos hablara Sagol (que combinan el entorno físico con el virtual), ya no sólo amplían los límites físicos de la clase, sino que son la clase misma. El delivery escolar se tornó un problema, pero también, la única solución posible en tiempos de pandemia; al menos para algunos optimistas pedagógicos. 
Claro está que, también, hay posiciones menos aferradas a este tipo de solución que no conciben el orden áulico sin la presencialidad. Al respecto Bombini (2020) expresa que "Hay algo del orden de los cuerpos presentes que es histórico en la escuela. Es decir, el disciplinamiento del cuerpo, que es a la vez el reconocimiento de que el cuerpo existe, no es algo que se puede borrar de un día para el otro. $Y$ no puede ser reemplazado fácilmente por otra cosa".

Otras opiniones, más categóricas pretenden "parar la escuela" (Rivero, 2020) o ven con cierta desconfianza la idea de una "educación virtual total" y prefieren denominarla "educación en tiempos de emergencia", bajo el supuesto de que la educación obligatoria sedimentó su funcionamiento a lo largo de siglos con otras características y que, por ende, habría que problematizar esta forma actual de pensar y hacer la escuela. Según lo que pude indagar, esta distinción de términos alude a que, hoy por hoy, no sólo no se disponen de los recursos y habilidades tecnológicas necesarias que minimicen la brecha digital y las desigualdades socio-educativas, sino porque se evalúa el riesgo de que se naturalice el modo virtual de enseñar como lo "normal". Bombini (2020) expresa su desconfianza respecto de que “...alguna corporación internacional con intereses de mercado en el campo educativo logre convencernos de que es posible dar clases solamente on line". También, algunos gremios están observando esta situación como de cierto peligro en tanto podría incidir en las políticas de Estado que conciban a la educación virtual como una estrategia de ahorro en materia de inversión en dicho sector.

Lo más o menos cierto es que, apenas los docentes y estudiantes de primaria, de secundaria y superior estaban asumiendo como habitual el uso de dispositivos móviles, así como la existencia complementaria de aulas físicas y de entornos virtuales de enseñanza y de aprendizaje, un acontecimiento pandémico aceleró de manera inusitada una experiencia de corrimiento a la virtualidad total, no planeada lo suficiente, tornando esa tibia y progresiva habituación y "al nuevo modo de estar contemporáneo" (Sibilia 2014), en una hiperrealidad.

Remontando la crónica de algunas ideas pensadas en estos años, hoy me pregunto: ¿Dónde fueron a parar mis planteos sobre la dimensión política del uso de dispositivos en el aula como formas de control, registro y hasta de escrache de la conducta del otro? ¿Cómo se redefinen las cuestiones de la vigilancia, el gobierno y la circulación del poder entre profesores y alumnos en tiempos de educación y coronavirus? ¿Será que esos alumnos despreciados por sus conductas proclives al uso (¿abusivo?) de las tecnologías en el aula, hoy serían, objeto de nuestra devoción docente? ¿Qué harían las "Lauras" y los "Leonardos" sin estudiantes que dispongan, hoy, de dispositivos varios y de conectividad para poder hacer que la máquina pedagógica funcione - como sea -, pero que funcione? Nada, o casi nada. 
El desafío por venir consistirá en encontrar nuevas formas de nombrar y de explicar estas mutaciones sociales y educativas, dando casi por hecho que después del "coronopticon", el "panótico" Foucaultiano y el "sinóptico" de Bauman, serán categorías a ser re significadas por los docentes y por quienes planifican las políticas educativas. ¿Qué nuevas prácticas materiales y simbólicas serán posibles en la educación, post COVID-19?

Como dice Oyarzún (2020) "Tenemos un contexto en el que la totalidad se escapa, se desplaza, se mueve, y sobre el que no hay muchas hipótesis que levantar". Estimo que, sin apremios, pero de modo sistemático, en materia de educación, hay que empezar a intentarlo.

\section{Bibliografía}

- Balardini, S. (2004). «Dedeejays y ciberchabones: subjetividades juveniles y tecnocultura». Revista Jóvenes №20. México.

Bauman, Z. (2001) La globalización: consecuencias humanas, Fondo de Cultura Económica, México, 2001.

. Bentham, J. (2004) El Panótico. Buenos Aires: Quadrata, Grupo Editor Montresor.

Cabello, R. (2010) Pliegues en la Tecnocultura, en Question, Revista especializada en Periodismo y Comunicación. Vol 1. №28. ISSN 1669-6581.

(2018) "20 minutos en el futuro. Distancias y relaciones interpersonales en el espacio digital", Pormeteo Libros.

- Burbules, N.; Callister, T. (2008) Educación: riesgos y promesas de las nuevas tecnologías de la información. Buenos Aires, Granica.

Deleuze, G. (1991) Posdata sobre las sociedades de control, en Christian Ferrer (Comp.) El lenguaje literario, To 2, Montevideo: Ed. Nordan.

Disponible en: http://www.fundacion.uocra.org/documentos/recursos/articulos/Posdata-sobrelas-sociedades-de-control.pdf

Di Paolo, B. (2014) La experiencia de las tecnologías de la información y la comunicación (tics) en el aula: disciplina, control y Noo-políticas, CUADERNOS FHyCS-UNJu, Nro. 45:11-25. Disponible en: http://www.scielo.org.ar/pdf/cfhycs/n45/n45a01.pdf

- Dussel, I. y Caruso, M. (1999) La invención del aula. Una genealogía de las formas de enseñar. Introducción, Cap. 1 y 2, Buenos Aires: Ed Santillana. 
Foucault, M. (1990) Tecnologías del yo y otros textos afines. Ediciones Paidós Ibérica, S.A. I.C.E. de la Universidad Autónoma de Barcelona, Barcelona - Buenos Aires - México. 1a ed. - Buenos Aires: Paidós, 2008.

(1991) La gubernamentalidad. En AA.VV: Espacios de Poder, La Piqueta: Madrid.

(2003) El Panoptismo. En: Vigilar y Castigar. Nacimiento de la Prisión, Buenos Aires:

Editorial Siglo XXI. 1a, ed.-Buenos Aires: Siglo XXI Editores Argentina (2002). Año de publicación original 1975, Gallimard.

Forni, P. (2010) Los estudios de caso: Orígenes, cuestiones de diseño y sus aportes a la teoría social. En la Revista MIRÍADA. Año 3, No. 5, Universidad del Salvador. Facultad de Ciencias Sociales. Instituto de Investigaciones en Ciencias Sociales (IDICSO), ISSN: 1851-9431

Gallo, S. (2010) Filosofía, enseñanza y sociedad de control. Cuestiones de Filosofía, 12,1-20.

Garay, L. (2000) Algunos conceptos para analizar Instituciones Educativas. Universidad Nacional de Córdoba.

Lazzarato, M. (2006) Políticas del acontecimiento. (P. E. Rodríguez, Trad.) Buenos Aires: Tinta Limón. Oyarzún, P. (2020) “La cabeza decapitada de la filosofía: Una conversación con Pablo Oyarzún”, por Federico Galende, El Desconcierto.

Disponible en: https://www.eldesconcierto.cl/libros/la-cabeza-decapitada-de-la-filosofia-unaconversacion-con-pablo-oyarzun/

Paredes, A. y otros (2015) Tipos de apoyo y la digitalización de las redes personales. El uso Facebook de adolescente rururbanos de Mendoza (Argentina), REDES- Revista hispana para el análisis de redes sociales Vol.26,\#1.

Peirone, F (2017) Mi realidad es aumentada, en Revista Anfibia, UNSM. Disponible en http://www.revistaanfibia.com/ensayo/mi-realidad-es-aumentada/

- Velásquez, L. (2012) Noo-política, el gobierno de la conducta de los demás: un acercamiento al pensamiento de Mauricio Lazzarato, Revista- Bogotá (Colombia) Vol. 7 №2.

- Rivero, Pedro (2002) Hay que parar la escuela. Redacción La Tinta. Disponible en: https://latinta.com.ar/2020/04/parar-escuela/?fbclid=IwAR3CR5ph1dpmRXp7YSnpDOe5FITiQJ8eguQdpjJWDwKUjxGpOIwiq2qAMY

Sagol, Cecilia (2013) Aulas aumentadas lo mejor de los dos mundos, Educ.ar. Disponible en: http://www.educ.ar/recursos/ver?rec_id=1162279/02/2013 
- Sibilia, P. (2012) ¿Redes o paredes? La escuela en tiempos de dispersión. Editorial Tinta Fresca.

(2014) La construcción de la subjetividad en red. Disponible en: https://www. youtube.com/watch? $v=f S i 5 u 5 r p 2 b 4$

(2015) Convivir y aprender entre redes o paredes. Disponible en:
https://www.youtube.com/watch? $v=c 87 B M S P 8 z 4 A$

Notas

ilturralde (2016) "Filmar y castigar", V Reunión Nacional de Investigadores/as en Juventudes Argentina, "Juventudes en disputa: permeabilidades y tensiones entre investigaciones y políticas". Rosario, Santa Fe. 21, 22 y 23 de noviembre de 2016.

ii A lo largo de todo este documento se utilizará el masculino genérico para referirse colectivos mixtos, a los efectos de una economía expresiva, sin discriminación de sexo, raza o etnia.

iii El panóptico es una idea arquitectónica que surge a fines del siglo XVIII, diseñada por Jeremy Bentham, para que los guardias de una cárcel puedan observar a los prisioneros, desde una torre central, sin ser vistos; Foucault (2003) utilizó este concepto para dar cuenta del control y vigilancia capilar sobre los cuerpos a partir de la existencia de la mirada omnipresente, de un "inspector", del que se sabe que está, pero que no es visto. Según su teoría, el panoptismo intenta imponer conductas al conjunto de la población a partir de la idea de que estamos siendo vigilados. Se busca generalizar un comportamiento típico dentro de unos rangos considerados normales, castigándose las desviaciones o premiándose el buen comportamiento.

iv La carta del profesor uruguayo que conmueve al mundo de la educación. Disponible en:

http://www.infobae.com/sociedad/2016/09/13/la-carta-del-profesor-uruguayo-que-conmueve-al-mundo-de-la-educacion/) (última visita 18/04/20).

v Dice Cabello (2018) “....a diferencia de otros períodos de la historia, actuamos en dos espacios complementarios: el espacio territorial y el espacio digital. En ellos establecemos relaciones, trabajamos, hacemos transacciones diversas, realizamos recorridos, jugamos. Ambos tipos de espacios (...) son producciones sociales que involucran actividad material y simbólica". Ver "20 minutos en el futuro. Distancias y relaciones interpersonales en el espacio digital", Prometeo Libros.

vi Black Mirror es una serie de televisión británica, de ciencia ficción, creada por Charlie Brooker. La serie alude al malestar contemporáneo sobre el mundo moderno y se caracteriza por presentar relatos que representan cómo la tecnología afecta al ser humano.

vii Sánchez, M (2020) Hipervigilancia en tiempos de pandemia, Revista N. Disponible en: https://www.clarin.com/revistaenie/panoptico-coronavirus-rastrea-

contactos_0_YKcFviWaa.html?utm_term=Autofeed\&utm_medium=Social\&utm_source=Facebook\&fbclid=IwAROMVaBpL-QIWvoxRhNpafGitoeb76cTrYjufTn5tvdaT6RRRk10Akf8Ho\#Echobox=1585707021 (última vista 18/04/20)

viii Ver la noticia en: https://larepublica.pe/tendencias/2020/04/18/video-cuarentena-argentina-profesor-sorprende-a-su-alumnodurmiendo-en-plena-clase-virtual-redes-sociales-viral-rddr/ (última visita 22/04/20020) 